\title{
Characteristics and Results of the Treatment of Multiple Myeloma in the Subject under the Age of 65 at the University Hospital of Yopougon in Abidjan, Côte d'Ivoire
}

\author{
Diebkilé Aïssata Tolo, Duni Sawadogo, Danho Clotaire Nanho, \\ Boidy Kouakou, N’Dogomo Méité, Roméo Ayémou, Paul Kouéhion, \\ Mozart Konan, Yassongui Mamadou Sékongo, Emeraude N’Dhatz, Ismaël Kamara, \\ Alexis Silué, Kouassi Gustave Koffi, and Ibrahima Sanogo
}

Department of Clinical Hematology, Yopougon Teaching Hospital, P.O. Box 632, Abidjan 21, Cote d'Ivoire

Correspondence should be addressed to Diebkilé Aïssata Tolo; aissata_tolo@yahoo.fr

Received 30 October 2013; Revised 7 December 2013; Accepted 8 December 2013

Academic Editor: Aldo Roccaro

\begin{abstract}
Copyright (C) 2013 Diebkilé Aïssata Tolo et al. This is an open access article distributed under the Creative Commons Attribution License, which permits unrestricted use, distribution, and reproduction in any medium, provided the original work is properly cited.
\end{abstract}

\begin{abstract}
We retrospectively studied 30 cases of multiple myeloma in patients under the age of 65, diagnosed from 1991 to 2005 in the clinical hematology department of the University Hospital of Yopougon that is a hospital incidence of 2.9 cases/year. The age of patients ranged from 34 to 64 years, with a mean age of 49 years and a sex ratio of 1.73 . The professional activity was variable with $3 \%$ of radiographers and $10 \%$ of farmers. Clinically, the dominant sign was bone pain in $83 \%$ of cases. Myeloma was secretory in $93 \%$ of cases. It was Ig G-type in $86 \%$, kappa-type in $66 \%$ of cases. $86 \%$ of patients were anemic, $20 \%$ had creatinine $>20 \mathrm{mg} / \mathrm{L}$, and $10 \%$ had serum calcium $>120 \mathrm{mg} / \mathrm{L}$. Geodes were found in $80 \%$ of cases. $53 \%$ were at stage III of DURIE and SALMON. Complications were infectious (33\%), renal (20\%), and hemorrhagic (7\%). Chemotherapy regimens were VAD (10\%), VMCP (30\%), and VMCP/VBAP $(60 \%)$ with $47 \%$ of partial responses, $33 \%$ of stable disease, and $7 \%$ of very good quality partial responses. The outcome developed towards death in $37 \%$ and causes of death were renal in $46 \%$ of cases. The median survival was only 5.1 months.
\end{abstract}

\section{Introduction}

Multiple myeloma or Kahler disease is a malignant proliferation of an abnormal plasma cell clone secreting a complete or incomplete immunoglobulin. It, respectively, accounts for $10 \%$ and $20 \%$ of malignant hemopathies in the Caucasian and Black American. It is a condition of the subject of more than 50 years of age. Its incidence increases with age: 5 per 100,000 individuals at the age of 60 and 20 per 100,000 individuals at the age of 80 . The average age at diagnosis is 64 years. It is slightly more common in men than in women [1].

Positive diagnosis of multiple myeloma is not always easy. It requires a combination of clinical arguments (general condition, bone syndrome), biological arguments (study of marrow, study of protein in the blood and urine, hemoglobin level, serum calcium, and creatinine), and radiological arguments (X-ray of the skeleton) [2].
The outcome is punctuated by multiple complications such as bone, renal, infectious, metabolic, neurological, hemorrhagic complications, and cachexia.

Initially the prognostic classification was based on that of DURIE and SALMON but currently it is the ISS (International Staging System) with two parameters albumin and $\beta 2$ microglobulin, which is used. In addition, some cytogenetic abnormalities such as del $(13 q), t(11 ; 14), t(4 ; 14), t(14 ; 16)$, and del (17p) have a major prognostic value. They have poor prognosis [3-6]. Mortality is 4.1/100,000 inhabitants/year in Europe [3].

Therapeutically, the treatment is not recommended for patients at stage I of DURIE and SALMON; on the other hand for stages II and III, treatment will be established taking into account the patient's age [3]. If, in developed countries, patients under the age of 65 receive intensive treatment with bone marrow graft particularly, this is not the case in 
Côte d'Ivoire. What were the results of treatment in these patients in our context of exercise and what were the features of their myeloma?

\section{Patients and Methods}

Our study was carried out in the Clinical Hematology Department of the University Hospital of Yopougon in Côte d'Ivoire. It was retrospective and descriptive and focused on the records of patients hospitalized for symptomatic multiple myeloma, diagnosed in the period from January 1991 to August 2005 by myelogram, the study of protein in the blood and urine, hemoglobin level, serum calcium, creatinine, skeletal X-ray according to SWOG criteria (Southern Western Oncology Group) and ROTI (multiple myeloma-related organ or tissue impairment: elevation of serum calcium, anemia, kidney failure, and bone lesions) $[6,7]$, and who had received chemotherapy. Thirty patients were included in the study. The patients with asymptomatic multiple myeloma and monoclonal gammopathies of undetermined significance were not selected. Each medical record was operated using an individual survey form with collection of epidemiological parameters (age, sex, occupation, and socioeconomic status), clinical parameters (performance status, bone pain), biological parameters (bone marrow plasma cells, type of monoclonal immunoglobulin, type of light chain, Bence Jones proteinuria, hemoglobin level, serum calcium, and creatinine), radiological parameters (geodes, demineralization, bone tumors, and bone fractures), evolutionary parameters (classification of DURIE and SALMON, progressive complications, and death), and therapeutic parameters according to the index of standardized generalized response (complete remission or CR, very good partial response or VGPR, partial response or $\mathrm{PR}$, stable disease, progression, and relapse) (Table 2).

The socioeconomic status was assessed using indirect criteria: habitat type, occupation, ability to meet the cost of prescriptions, and number of dependent children.

CR corresponds to the negativity of monoclonal immunoglobulin in the blood and urine and to bone marrow plasma cells $<5 \%$.

VGPR corresponds to serum monoclonal immunoglobulin decreased by $90 \%$ and to urinary immunoglobulin $<100 \mathrm{mg} / 24 \mathrm{H}$.

PR corresponds to serum monoclonal immunoglobulin decreased by $50 \%$, urinary monoclonal immunoglobulin decreased by $90 \%$, and free light chains decreased by $50 \%$.

Stable disease corresponds to the lack of criteria for CR, VGPR, and PR.

Progression criteria are $25 \%$ increase of serum or urine monoclonal immunoglobulin or free light chains assay, an increase of $10 \%$ of the bone marrow plasma cells, appearance of new bone or extra bone lesions, and a level of calcium greater than $2.65 \mathrm{mmol} / \mathrm{L}$.

The criteria for relapse are appearance of new bone or extra bone lesions, a level of serum calcium greater than $2.65 \mathrm{mmol} / \mathrm{L}$, hemoglobin level lowering to $2 \mathrm{~g} / \mathrm{dL}$, and a level of creatinine greater than $20 \mathrm{mg} / \mathrm{L}(177 \mu \mathrm{mol} / \mathrm{L})$; the

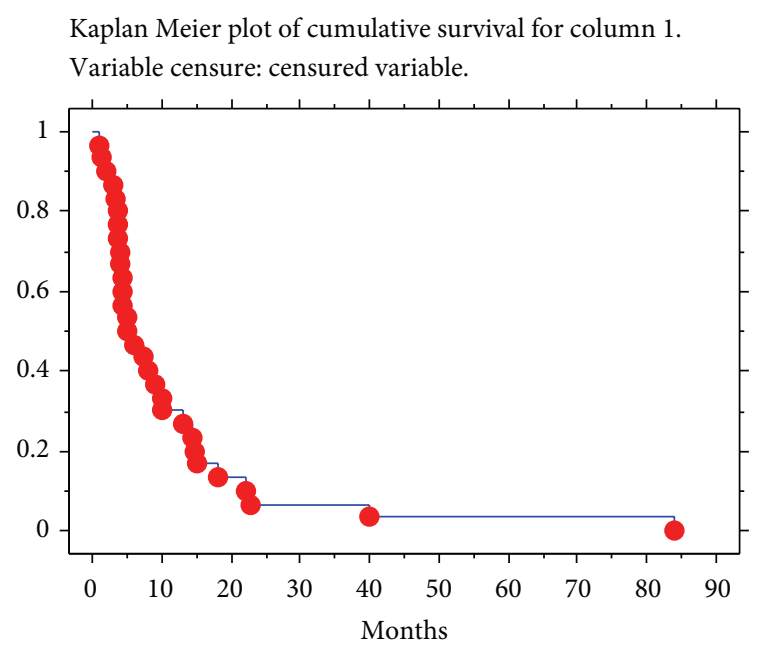

FIGURE 1: Overall survival curve.

monoclonal component alone is not taken into account for relapse [7].

Therapeutically, three chemotherapy regimens were used in our patients (VAD: vincristine, adriamycin, dexamethasone protocol, VMCP: vincristine, melphalan, cyclophosphamide, prednisone protocol, VMCP/VBAP: VMCP/vincristine, carmustine, adriamycin, prednisone alternate protocol) in spaced treatments of 4 to 6 weeks associated with adjuvant therapies (bisphosphonates, antiemetics, and potassium).

Data were analyzed using Epi-Info software version 6.04b, Statview. The calculation of overall survival was performed according to the Kaplan Meier method with the existence in the record of an inclusion date (admission date) and a date of final assessment (date of death or the latest information mentioned in day, month, and year (dd-mm-yyyy)) (Figure 1).

\section{Results}

From January 1991 to August 2005, the diagnosis of symptomatic multiple myeloma was made in 30 patients under the age of 65 , out of a total number of 44 cases of myeloma. The epidemiological, clinical, and biological features of these patients are summarized in Table 1.

\section{Discussion}

This study of multiple myeloma was carried out because very few data exist on the international level concerning the myeloma of the Ivorian.

The Clinical Hematology Department of the University Hospital of Yopougon is the only center of therapeutic management of hematological malignancies.

Out of a total of 44 cases of symptomatic multiple myeloma diagnosed from 1991 to 2005, in 15 years, we had a hospital incidence of 2.9 cases/year. The prevalence increased steadily with age: $10 \%$ among patients under the age of 40 , $33 \%$ among $40-51-y e a r-o l d ~ p a t i e n t s$, and $57 \%$ among $52-$ 64-year-old patients. In addition, patients under the age of 
TABLE 1: Epidemiological, clinical, and biological features of patients.

\begin{tabular}{|c|c|}
\hline Variables & Numbers (\%) \\
\hline \multicolumn{2}{|c|}{ Age (years): average and extremes: 49 (34-64) } \\
\hline$<40$ & $3(10)$ \\
\hline $40-51$ & $10(33)$ \\
\hline $52-64$ & $17(57)$ \\
\hline \multicolumn{2}{|l|}{ Sex: sex ratio: 1.73} \\
\hline Male & $19(63)$ \\
\hline Female & $11(37)$ \\
\hline \multicolumn{2}{|l|}{ Professional occupations } \\
\hline Executives & $8(27)$ \\
\hline Housewives & $4(13)$ \\
\hline Informal sector & $4(13)$ \\
\hline Others & $14(47)$ \\
\hline \multicolumn{2}{|l|}{ Socioeconomic status } \\
\hline Low & $8(27)$ \\
\hline Average & $17(57)$ \\
\hline High & $5(16)$ \\
\hline \multicolumn{2}{|l|}{ Performance status } \\
\hline 0 and 1 & $3(10)$ \\
\hline 2 and 3 & $24(80)$ \\
\hline 4 & $3(10)$ \\
\hline \multicolumn{2}{|l|}{ Bone syndrome } \\
\hline Bone pains & $25(83)$ \\
\hline Bone tumors & $1(3)$ \\
\hline Fractures & $10(33)$ \\
\hline \multicolumn{2}{|l|}{ Bone marrow plasma cells } \\
\hline 10 to $30 \%$ & $18(60)$ \\
\hline$>30$ & $12(40)$ \\
\hline \multicolumn{2}{|l|}{ Whether secretory or not } \\
\hline Secretory & $28(93)$ \\
\hline Nonsecretory & $2(7)$ \\
\hline \multicolumn{2}{|c|}{ Type of monoclonal immunoglobulin } \\
\hline Ig G & $26(86)$ \\
\hline Ig A & $2(7)$ \\
\hline Light chains myeloma & $2(7)$ \\
\hline \multicolumn{2}{|l|}{ Type of light chain } \\
\hline Kappa & $20(86)$ \\
\hline Lambda & $2(7)$ \\
\hline Undetermined & $2(7)$ \\
\hline \multicolumn{2}{|l|}{ Hemoglobin level (g/dL) } \\
\hline$<8$ & $13(43)$ \\
\hline $8-12$ & $13(43)$ \\
\hline$>12$ & $4(14)$ \\
\hline \multicolumn{2}{|l|}{ Serum creatinine $(\mathrm{mg} / \mathrm{L})$} \\
\hline$<20$ & $24(80)$ \\
\hline$>20$ & $6(20)$ \\
\hline \multicolumn{2}{|l|}{ Calcium (mg/L) } \\
\hline$<120$ & $27(90)$ \\
\hline$>120$ & $3(10)$ \\
\hline \multicolumn{2}{|c|}{ Bence Jones proteinuria (mg/24 H) } \\
\hline$<12$ & $24(80)$ \\
\hline$>12$ & $6(20)$ \\
\hline
\end{tabular}

Other professional activities: radiographer, farmers, policeman, traders, and teachers.
TABLE 2: Radiological, evolutional, and therapeutic features.

\begin{tabular}{|c|c|}
\hline Variables & Numbers (\%) \\
\hline \multicolumn{2}{|l|}{ Radiological signs } \\
\hline Geodes & $24(80)$ \\
\hline Demineralization & $12(40)$ \\
\hline Bone tumors & $1(3)$ \\
\hline Fractures & $10(33)$ \\
\hline \multicolumn{2}{|l|}{ Seats of fractures } \\
\hline Femur & $6(20)$ \\
\hline Humerus & $2(7)$ \\
\hline Rib & $1(3)$ \\
\hline Tibia & $1(3)$ \\
\hline \multicolumn{2}{|l|}{ Stage of DURIE and SALMON } \\
\hline Stage I & $0(0)$ \\
\hline Stage II & $14(47)$ \\
\hline Stage III & $16(53)$ \\
\hline \multicolumn{2}{|l|}{ Complications } \\
\hline Acute renal failure & $2(7)$ \\
\hline Chronic renal failure & $2(7)$ \\
\hline Infectious & $10(33)$ \\
\hline Hemorrhagic & $2(7)$ \\
\hline \multicolumn{2}{|l|}{ Therapeutic protocols } \\
\hline VAD & $3(10)$ \\
\hline VMCP & $9(30)$ \\
\hline VMCP/VBAP & $18(60)$ \\
\hline \multicolumn{2}{|l|}{ Therapeutic responses } \\
\hline CR & $0(0)$ \\
\hline VGPR & $2(7)$ \\
\hline $\mathrm{PR}$ & $14(47)$ \\
\hline Stable disease & $10(33)$ \\
\hline Progression & $4(13)$ \\
\hline Relapse & $0(0)$ \\
\hline \multicolumn{2}{|l|}{ Outcome } \\
\hline Living and on treatment & $6(20)$ \\
\hline Lost to followup & $13(43)$ \\
\hline Dead & $11(37)$ \\
\hline \multicolumn{2}{|l|}{ Causes of death } \\
\hline Progression & $3(27)$ \\
\hline Renal complication & $5(46)$ \\
\hline Infectious complication & $3(27)$ \\
\hline Survival (median and extreme values in months) & $5.1(0-84)$ \\
\hline
\end{tabular}

65 accounted for $68.2 \%$ of all of our myelomas. Thus, the predominance of young patients under the age of 65 is one of the epidemiological features of our myelomas, whereas, in Europe, $40 \%$ of patients are under the age of 65 and less than $2 \%$ are under the age of 40 [8]. The average age of onset in Europe is typically around 65 to 70 years $[6,8]$. The average age of our study population was 49 years, with extremes of 34 and 64. Our low average age is due to our type of sampling (study population aged under 65), and also due to the age pyramid of the African populations. However, all authors agree that myeloma is rare before the age of 40 and that it is 
predominant among the male subject, as shown in our study $[4,6,9]$.

In our study population, the occupation was very variable, ranging from executives to the informal sector and housewives. Exposure to ionizing radiation is the only established risk factor. This risk was found in one patient who was a radiographer. No case of family myeloma was noted. Some authors mentioned environmental factors (pesticides, herbicides, and fertilizers), especially among farmers who accounted for $10 \%$ of our study population [1].

Clinically, a bone syndrome was found in $83 \%$ of cases. It was characterized by bone pains associated or not with a bone tumor $(3 \%)$ or a fracture $(33 \%)$. Thus, bone pain was the dominant clinical sign in our patients, not relieved by conventional analgesics. The performance status was 2 or 3 in $80 \%$ of cases, most often associated with asthenia due to anemia or other evolutionary complications particularly recurrent infections (33\%), renal failure (20\%), and bleeding (7\%). Infections were urogenital in 5 cases, pulmonary in 2 cases, ENT in 1 case, mucocutaneous in 1 case, and musculoskeletal in 1 case $[1,6]$.

Paraclinically, anemia was found in $86 \%$ of cases. This anemia was severe $<8 \mathrm{~g} / \mathrm{dL}$ in $43 \%$ of cases in our study population. In the literature we have, anemia is observed in 40$73 \%$ of cases $[6,9]$. Bone marrow plasma cells were between 10 and $30 \%$ in $60 \%$, the monoclonal immunoglobulin of type $\mathrm{G}$ in $86 \%$, the kappa light chains in $66 \%$, and secretory myeloma in $93 \%$. Creatinine was $<20 \mathrm{mg} / \mathrm{L}$ in $80 \%$ and serum calcium $<120 \mathrm{mg} / \mathrm{L}$ in $90 \%$. Radiological signs were dominated by geodes $(80 \%)[10,11]$. No patient received magnetic resonance imaging $(\mathrm{MRI})$ or serum determination of free light chains or cytogenetic examination for the detection of chromosomal abnormalities.

In terms of outcome, myeloma was at stage II of DURIE and SALMON in $47 \%$ of cases and at stage III in $53 \%$ of cases. The ISS (International Staging System) could not be assessed because the determination of $\beta 2$ microglobulin could not be performed in the majority of patients.

Therapeutically, we only resorted to chemotherapy associated with bisphosphonates in our patients because we did not have bone marrow graft. Three chemotherapy regimens were used: VAD protocol (10\%), VMCP protocol (30\%), and VMCP/VBAP alternate protocol (60\%). These treatments resulted in $47 \%$ of partial responses, $7 \%$ of very good partial responses, $33 \%$ of stable disease, and $13 \%$ of progression. No case of complete remission or relapse was recorded [7]. The absence of complete remission is due to the lack of intensification and the poor compliance by the fact that most patients do not complete their treatment plan, mostly for financial problems, given that $84 \%$ of our patients were of low socioeconomic conditions.

Four parameters have influenced our responses to treatment:

(i) the absence of bone marrow transplant and new drugs for multiple myeloma (Bortezomib, IMiDs),

(ii) the large number of patients lost to followup (43\%),

(iii) the fact that the Black has a mortality rate higher than the Caucasian [12], (iv) the problems of access to antimitotics: patients who are mostly of low socioeconomic status are obliged to buy medicines at exorbitant prices for their treatment.

Despite this, our results can be considered acceptable since our complete remission rate was $47 \%$. This rate is close to that of Alexanian et al. in the US and Wan in China who have obtained, respectively, $55 \%$ and $59.09 \%$ with a protocol including vincristine, VAD $[13,14]$.

Our challenge that is to improve our response rate will probably be taken up because the service has new treatments for multiple myeloma.

Concerning the outcome of patients, 13 were lost to followup, that is, $43 \%$, 11 had died, that is, $37 \%$, and 6 were still alive and on treatment, that is, $20 \%$. We have no data concerning the monitoring of the cohort of 6 patients alive from 2005 to 2013 . This is the reason why the maximum survival time was 84 months in our Kaplan Meier curve. So there is no median followup of this cohort. The causes of death were renal in $47 \%$ and infectious in $27 \%$, related to the progression of the disease in $27 \%$. The median overall survival was 5.1 months with extremes ranging from 0 to 84 months. The probability of survival at 6 months was $51 \%$ and at 3 years $6.7 \%$. But it should be noted that currently the gold standard in subjects under the age of 65 is the VTD (velcade, thalidomide, dexamethasone) protocol, and we have this protocol at our disposal since October 2010. But only well-off patients have access to it, given its relatively high cost. But in our regions, there is no international clinical trial for multiple myeloma at the moment.

\section{References}

[1] A. B. Chaubert, F. Delacretaz, and P. M. Schmidt, "Myélome multiple," Schweizerische Medical Forum, vol. 5, pp. 309-316, 2005.

[2] R. Bataille, "Myélome multiple: traitements symptomatiques et antitumoraux," in Encycl Méd Chir, Hématologie, p. 17, Elsevier, Paris, France, 1996.

[3] J.-L. Harousseau and M. Dreyling, "Multiple myeloma: ESMO clinical practice guidelines for diagnosis, treatment and followup," Annals of Oncology, vol. 21, no. 5, pp. v155-v157, 2010.

[4] W. J.-Dong, M. Chang-Ki, and H. Kyungja, "Impact of genetic abnormalities on the prognoses and clinical parameters of patients with multiple myeloma," Annals of Laboratory Medicine, vol. 33, no. 4, pp. 248-254, 2013.

[5] D. E. Reece, "Recent trends in the management of newly diagnosed multiple myeloma," Current Opinion in Hematology, vol. 16, no. 4, pp. 306-312, 2009.

[6] A. Palumbo and C. Cerrato, "Diagnosis and therapy of multiple myeloma," The Korean Journal of Internal Medicine, vol. 28, no. 3, pp. 263-273, 2013.

[7] J. M. Bird, R. G. Owen, S. D’Sa et al., "Guidelines for the diagnosis and management of multiple myeloma 2011," British Journal of Haematology, vol. 154, no. 1, pp. 32-75, 2011.

[8] A. Oranger, C. Carbone, and M. Grano, "Cellular mechanisms of multiple myeloma bone disease," Clinical and Developmental Immunology, vol. 2013, Article ID 289458, 14 pages, 2013.

[9] A. Dispenzieri and R. A. Kyle, "Multiple myeloma: clinical features and indications for therapy," Best Practice and Research, vol. 18, no. 4, pp. 553-568, 2005. 
[10] R. A. Kyle, M. A. Gertz, T. E. Witzig et al., "Review of 1027 patients with newly diagnosed multiple myeloma," Mayo Clinic Proceedings, vol. 78, no. 1, pp. 21-33, 2003.

[11] G. R. Shaw, "Nonsecretory plasma cell myeloma-becoming even more rare with serum free light-chain assay: a brief review," Archives of Pathology and Laboratory Medicine, vol. 130, no. 8, pp. 1212-1215, 2006.

[12] D. Pulte, M. T. Redaniel, H. Brenner, L. Jansen, and M. Jeffreys, "Recent improvement in survival of patients with multiple myeloma: variation byethnicity," Leukemia Lymphoma. In press.

[13] R. Alexanian, B. Barlogie, and S. Tucker, "VAD-based regimens as primary treatment for multiple myeloma," American Journal of Hematology, vol. 33, no. 2, pp. 86-89, 1990.

[14] J. Wan, "Therapeutic efficacy analysis of VD regimen and VAD regimen for multiple myeloma," Zhongguo Shi Yan Xue Ye Xue Za Zhi, vol. 21, no. 3, pp. 647-649, 2013. 


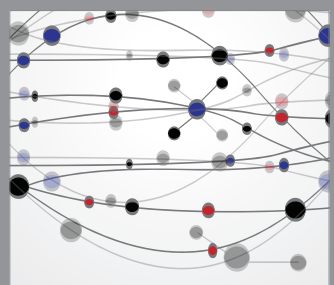

The Scientific World Journal
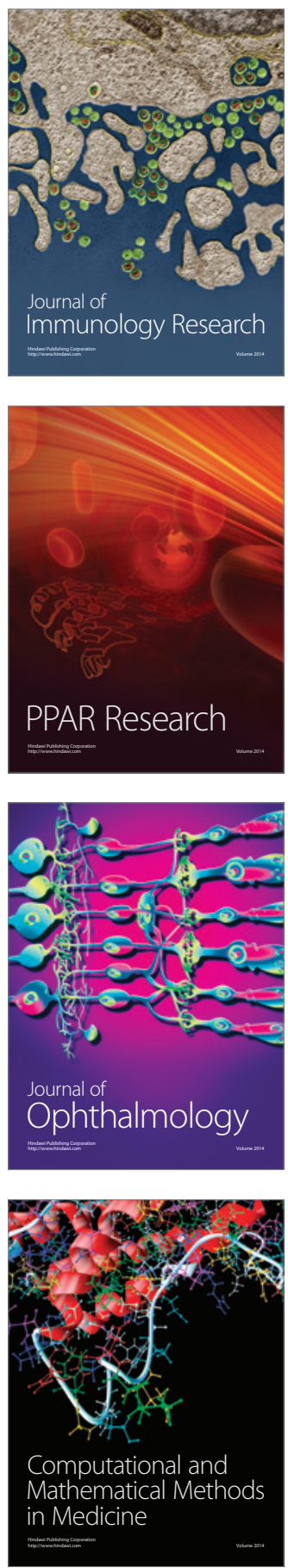

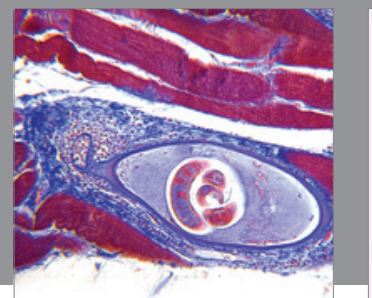

Gastroenterology

Research and Practice
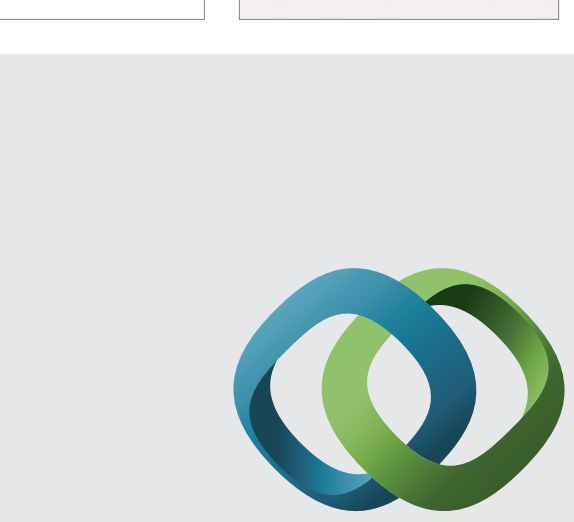

\section{Hindawi}

Submit your manuscripts at

http://www.hindawi.com
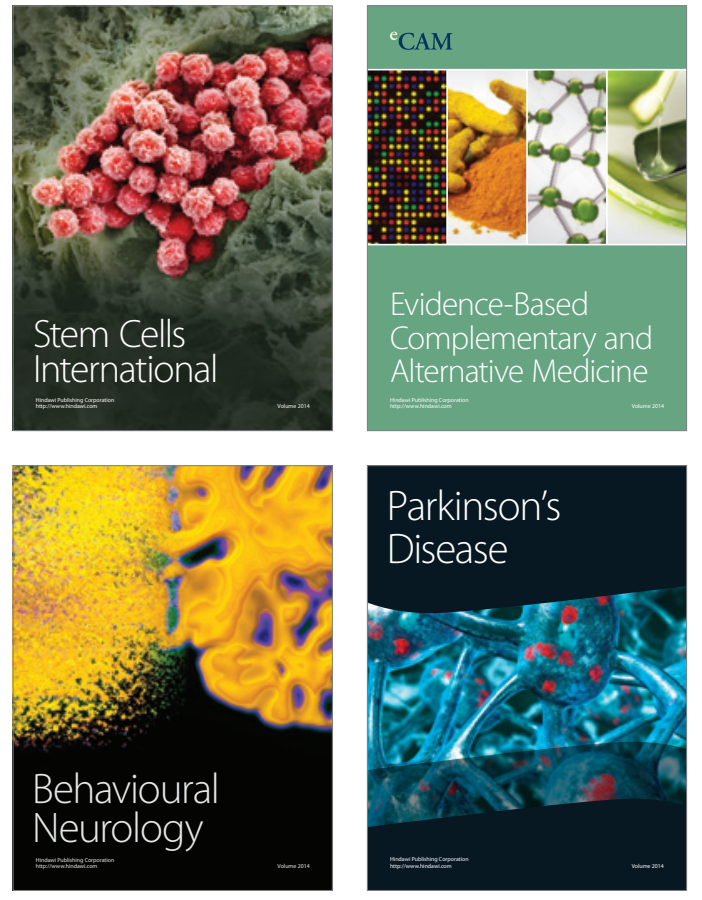
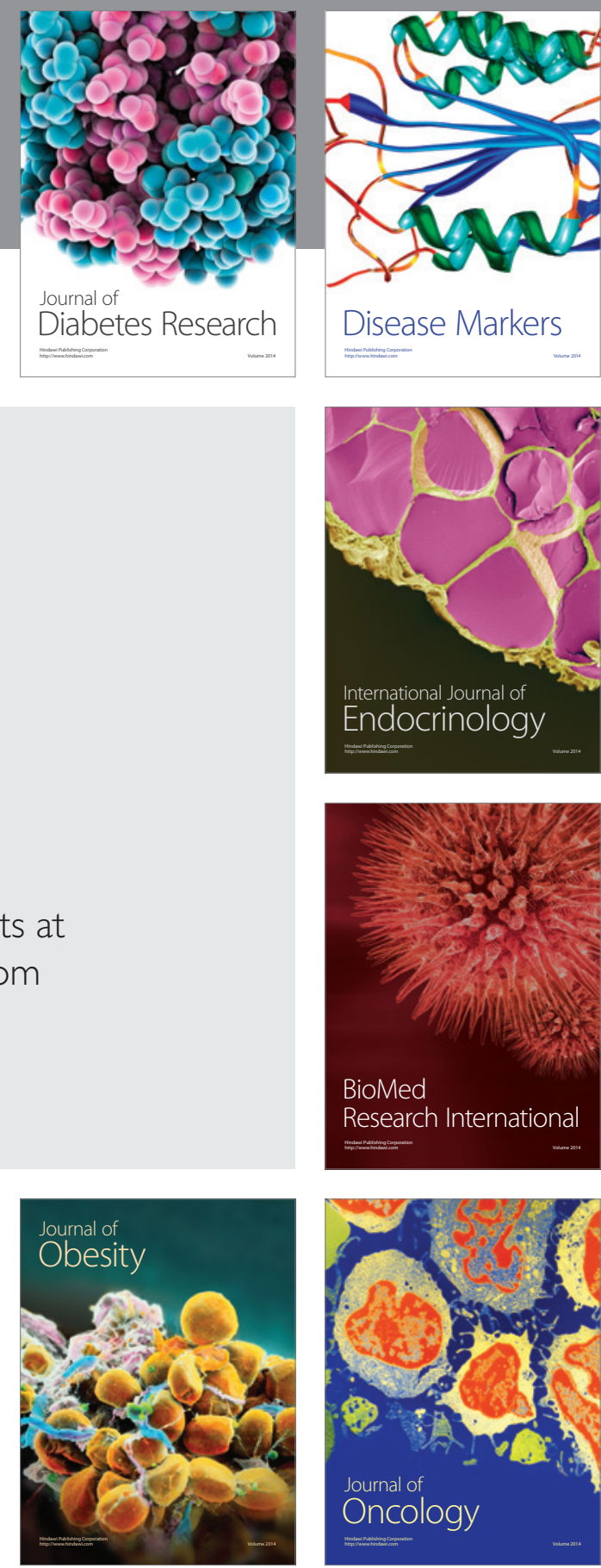

Disease Markers
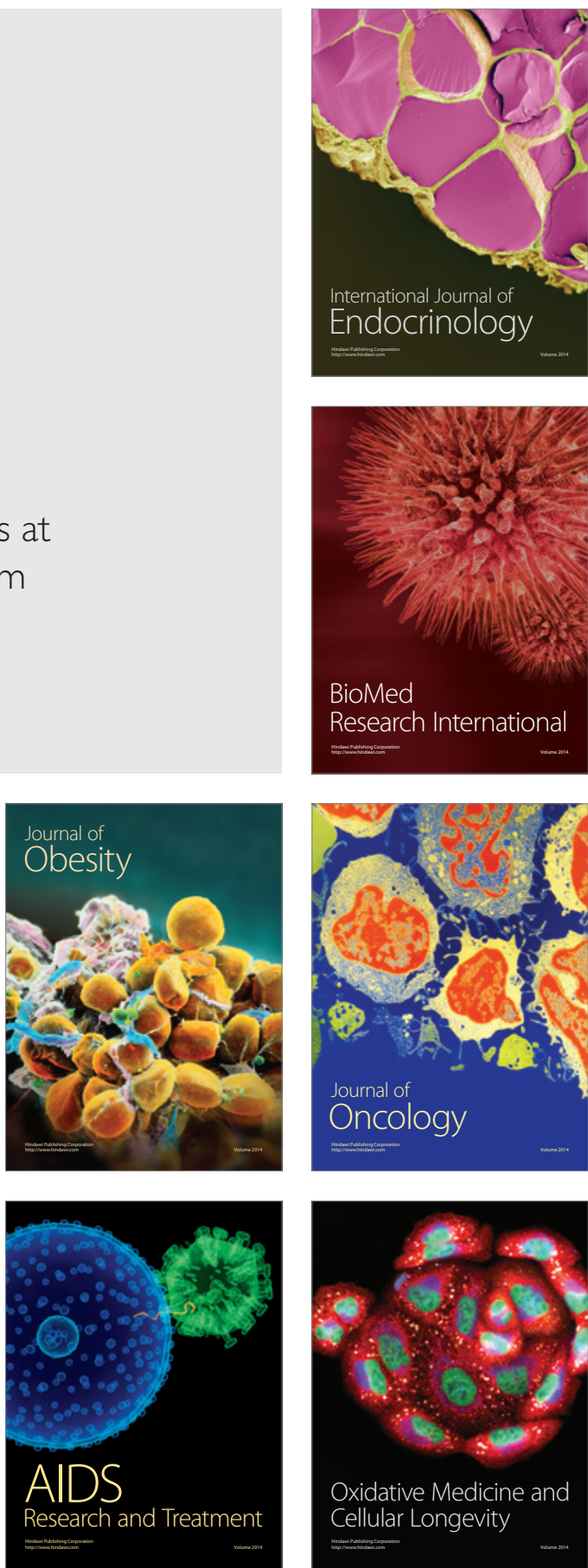